\title{
Developmental Difficulties Prevalence and Management Capacities Among Children Including Genetic Disease in a Coastal District of India
}

\author{
Koteswara Rao Pagolu* \\ Department of Biochemistry, Andhra University, India \\ *Corresponding author: Koteswara Rao Pagolu, Department of Biochemistry, Andhra University, Andhra Pradesh, India
}

ARTICLE INFO

Received: 㓞 September 03, 2021

Published: 䋓 September 21, 2021

Citation: Koteswara Rao Pagolu. Developmental Difficulties Prevalence and Management Capacities Among Children Including Genetic Disease in a Coastal District of India. Biomed J Sci \& Tech Res 38(5)-2021. BJSTR. MS.ID.006220.

Keywords: Child Health Screening; Developmental Delays; District Early Intervention Center; Genetic Disease Management; Health Records; Infrastructural Facility

\begin{abstract}
Introduction: The present study was aimed to find out the prevalence of DD's in Visakhapatnam, one of the north coastal districts of Andhra Pradesh, India during a span of five years.

Methods: A cross-sectional investigation was held at District early intervention center (DEIC), Visakhapatnam from 2016 to 2020. To identify the pattern and trend of different DD's including seasonal variations, a retrospective analysis of the health center's inpatient database for the past 5 years was done. Male and female children aged 2 months-18 years are included in the study with the prior permission of the concerned medical officer. Qualitative and quantitative examination viewpoint were utilized to evaluate the administration practices on (developmental delays) DD's at the chosen health facilities.
\end{abstract}

Results: Among 26,423 cases, children with birth defects are 962, 2229 with deficiencies, 7516 with diseases, and 15716 with disabilities were admitted during the study period. From birth defects, congenital deafness occurred in large numbers with $22.66 \%$, and neural tube defect observed in a small number of cases with $0.83 \%$ during the period. From the side of deficiencies, severe acute malnutrition has mostly occurred $(66.80 \%)$ and a small number of children were affected with goiter $(1.70 \%)$.

Conclusion: Through this study, it is observed that the incidence of birth defects, as well as genetic disease burden, is high in the Visakhapatnam district. Hence there is a need for strengthening of management services for these diseases in this region.

\section{Introduction}

Birth defects (BD's) are one of the most frequent conditions that pediatricians experience in clinical practice. The major clinical conditions can be grouped as genetic disorders and congenital anomalies [1]. When the child fails to meet developmental milestones related to daily living, it is considered as developmental delay (DD) [2]. Over the past 12 years, the occurrence of DD's has increased by three percent in children under the age group of five and has reached up to $15 \%$ [3]. Worldwide, 1.5\% -19.8\% of children have DD. In India, the children who are discharged from the sick newborn unit have a high prevalence of DD's. The government of India initiated the 4D's approach through District early intervention center (DEIC) for the treatment and support of these challenged children [4]. For ensuring proper health care for children, it is necessary for early detection and in time management of disorders [5]. If the DD's are not intervened in time, it can lead to manifested functional disabilities in children. In such cases, the children are being subjected to treatment after the identification of these disabilities [6].

DEIC is engaged with a team consisting of medical officers, Pediatrician, Paramedics, and staff nurses and also provides referral support to children (1month-18 years) diagnosed with health conditions during the screening period. The present study 
investigates the prevalence of the conditions screened among the children attending the DEIC center at Visakhapatnam for the period of 5 years (January-2016 to December-2020) and also to find out the adequacy of institutional capacities in child health screening.

\section{Materials and Methods}

The present study was aimed to assess the burden of DD's and their trend in the DEIC, Visakhapatnam, and also to analyze the availability of manpower as well as infrastructure, so as to suggest possible improvements in the management of such diseases. Necessary permission was obtained from the institutional ethics committee, Andhra University, and also from the Andhra Medical College in this regard. In this center, BD's were diagnosed by the pediatrician through a medical examination. As part of the study, the registers of the patients admitted at the health center with DD's during 2016-2020 were reviewed on the lines of patient sex, age and health condition including genetic disorder. Assessment of the institutional capacities in child health screening was done taking into cognizance of the Rashtriya bal swasthya karyakram (RBSK) norms which were initiated by the government of India. During and after the survey privacy and confidentiality were ensured. SPSS Software Version 19 was used for data entry and analysis (SPSS South Asia Pvt. Ltd, Banglore, Karnataka).
Quantitative and Qualitative research methodologies were utilized to evaluate the administration rehearses on (developmental delays) DD's at the chosen health facilities. The study instruments were office agenda; record survey for specific administrations over the most recent one year; and semi-organized schedule of interview for administration providers. Security and privacy were kept up during and after the review. Information passage and investigation were done inSPSS Software Version 19 (SPSS South Asia Pvt. Ltd, Banglore, Karnataka).

\section{Results}

Total 26423 children with DD's consulted the DEIC during the investigation time frame. These children were classified under the 4D's (i.e., defects, deficiencies, diseases, and disabilities) approach. From the results tabulated in Graph 1, it can be observed that children below 6 weeks age group are 4786 (18.11\%) numbers, of which 2508 are male and 2206 are female. The age group of one and a half month old to 3 years old, total 6397 (24.20\%) kids was there of which 3619 are male and 2778 are female; and in 3 years to 6 years category, 3325 are male and 2006 are female totaling to $5331(20.17 \%)$ numbers. Children between 6 years to 18 years old are 9909 (37.50\%) numbers involving 5408 males and 4501 females. The children having conditions under each of the 4D's are tabulated under the graph $2,3,4$, and 5 respectively.

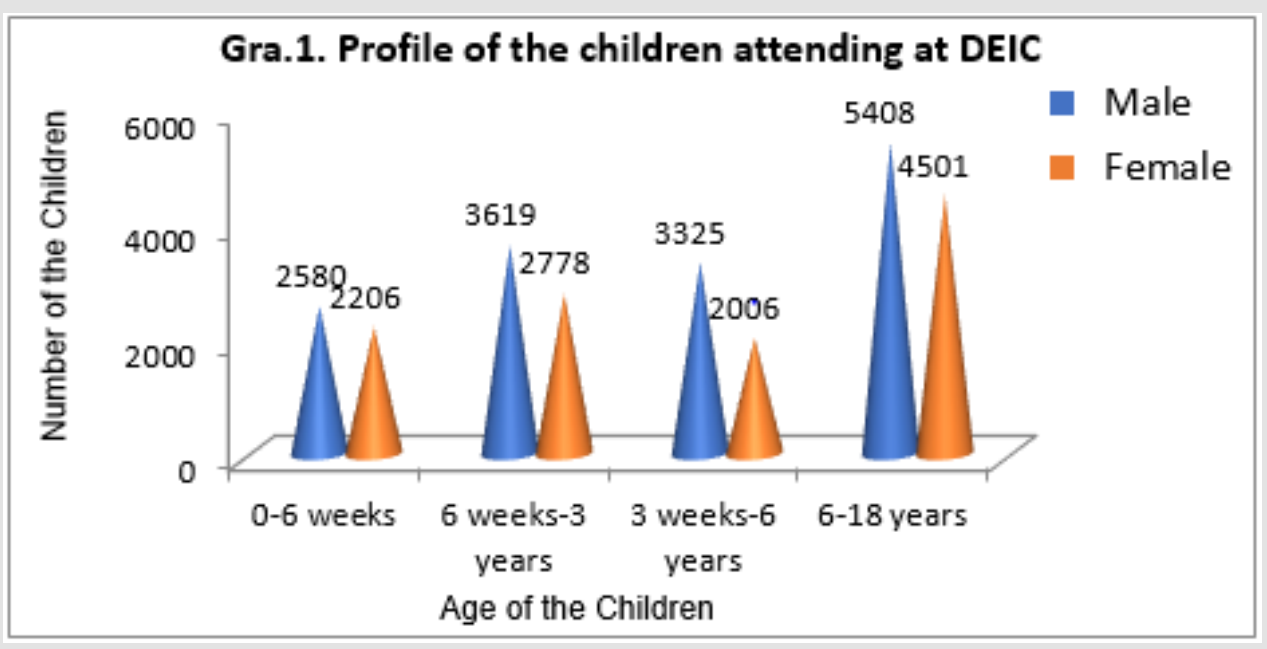

Graph 1: Profile of the children attending at DEIC.

Graph 2 shows the distribution of children according to the presence of BD's for the last five years. The different birth defects screened by the center are neural tube defect, down's syndrome, cleft lip \& palate, club foot, developmental dysplasia of the hip, congenital cataract, congenital deafness, congenital heart diseases, and retinopathy of prematurity. Out of 135 BD's cases identified in 2016, the majority of cases were cleft lip \& palate cases with $86(63.70 \%)$ numbers followed by congenital heart disease cases with $33(24.44 \%)$ numbers. In 2017, the total BD's are 157 out of which club foot cases were maximum with 57 (36.30\%) numbers and congenital heart diseases cases come next with 47 (29.93\%) numbers. In 2018 total number of these cases are 246, of which club foot cases were maximum with 73 (29.67\%) numbers followed by congenital deafness cases with $66(26.82 \%)$ numbers. During the year 2019, a total of 298 cases was identified with congenital deafness in a maximum of 95 (31.87\%) numbers followed by cleft lip \& palate cases in 66 (22.14 \%) numbers. For the year 2020, a total of 126 cases was found, comprising the highest number of club 
foot cases in 45 (35.71\%) children and congenital deafness cases in $36(28.57 \%)$ children. From all the above it is observed that the highest number of BD's occurred in 2019 and dropped to their lowest among children in 2020. However, while studying the trends in BD's data for a selected five-year period, it was observed that the prevalence rate of cleft lip \& palate, club foot, and congenital deafness cases is much higher.

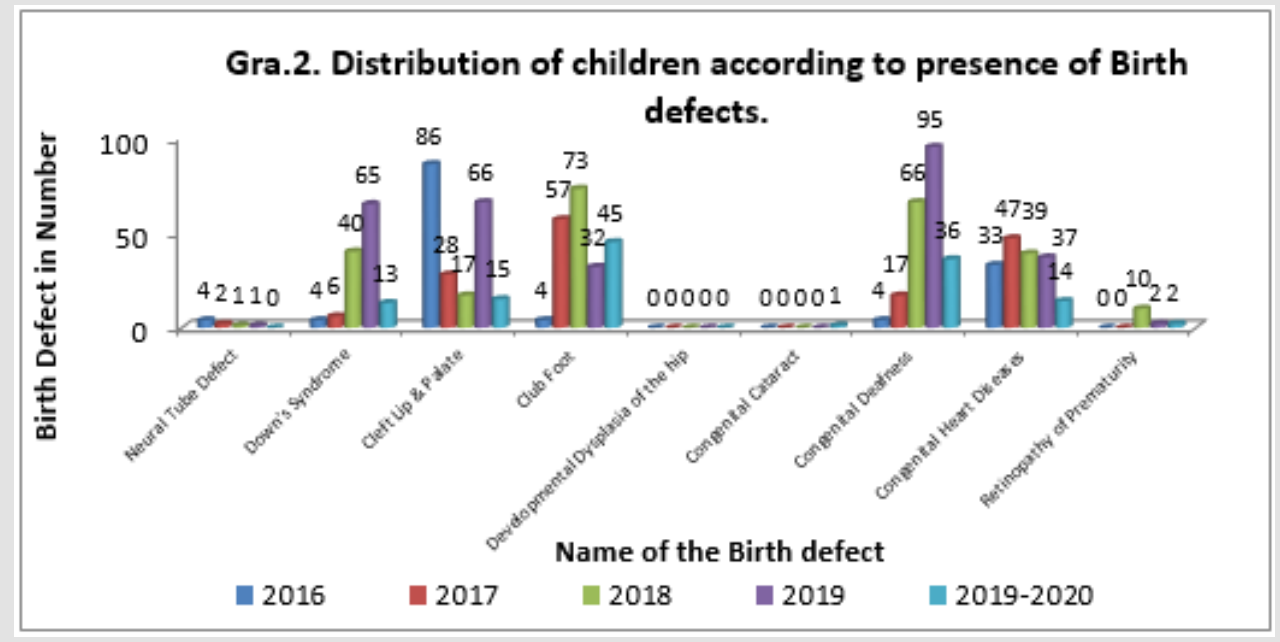

Graph 2: Distribution of children according to presence of birth defects.

Graph 3 shows the distribution of children according to the presence of deficiencies. These are severe anemia, vitamin A deficiency (bigot's spot), vitamin-D deficiency, severe acute malnutrition, and goiter. The number of deficiencies is 1496, 296, 116,261 , and 60 for the years 2016, 2017, 2018, 2019, and 2020, respectively from the center. The deficiencies have diminished from a maximum of 1496 cases during the year 2016 to a minimum of
60 cases in the year 2020. During the total period of the study, it is observed that most of the children are suffering from severe acute malnutrition followed by severe anemia. To overcome this problem, a nutritional rehabilitation center was attached to this institute and is located in King George hospital, Visakhapatnam. With the help of this rehabilitation center, the nutritional status of the needy children is being improved.

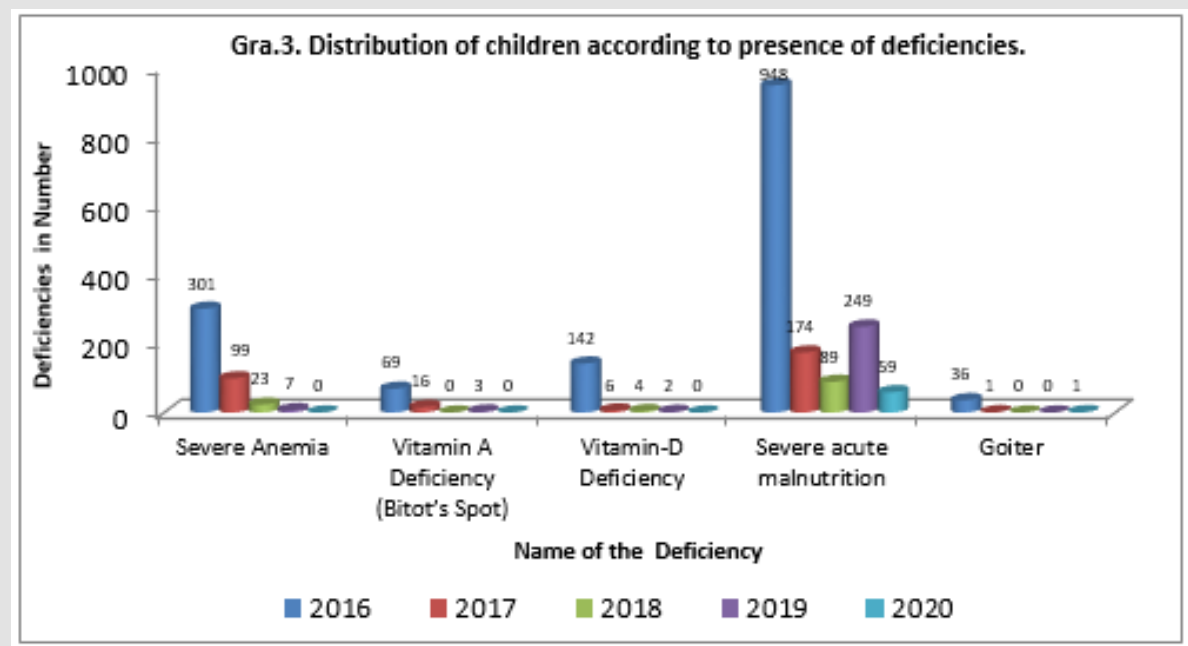

Graph 3: Distribution of children according to presence of deficiencies.

Graph 4 indicates the distribution of children according to the presence of diseases. Among the list of diseases, skin conditions, otitis media, rheumatic heart disease, reactive airway disease, dental caries, and convulsive disorders were present. The number of diseases is $3297,1197,1190,1473$, and 359 from the center for the years 2016, 2017, 2018, 2019, and 2020, respectively. During the total period of the study dental caries were found in a maximum number of children and the second most common disease found was otitis media. Year by year there is a gradual decline in the number of cases with diseases and this is due to public awareness and stringent steps taken by the government towards diseases. 


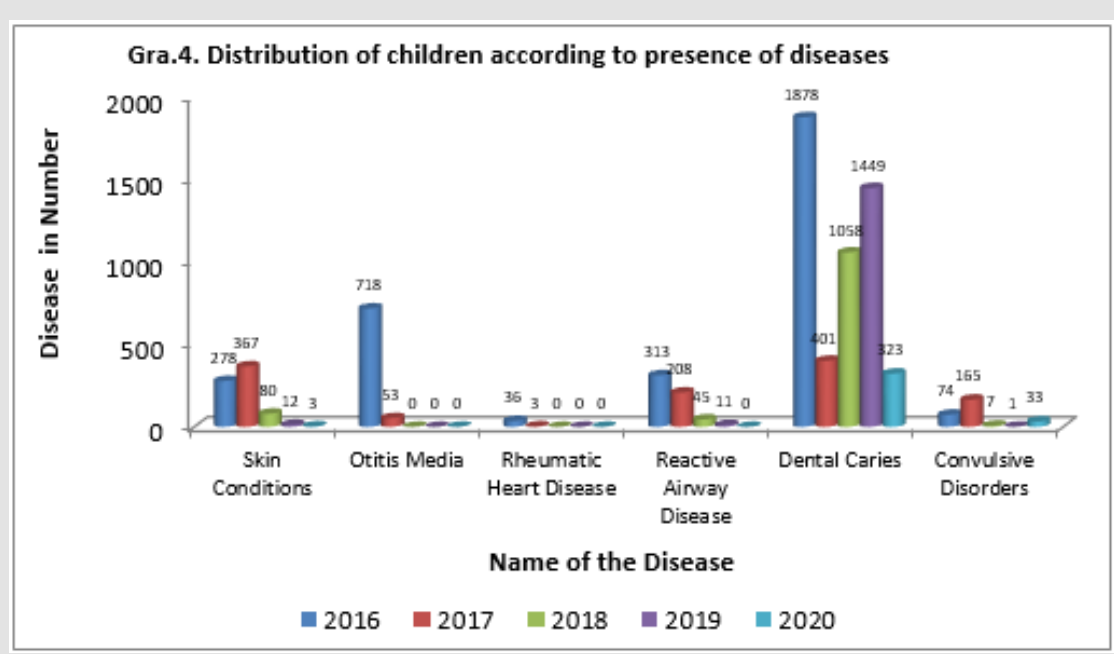

Graph 4: Distribution of children according to presence of diseases.

Graph 5 demonstrates the distribution of children according to the presence of disabilities. Among these vision impairment, hearing impairment, neuromotor impairment, motor delay, cognitive delay, language delay, behavior disorder (autism), learning disorder, attention deficit hyperactivity disorder, and other inabilities like growing up concerns, substance abuse, feel depression, delay in period cycles, torment during the period, agony or copying sensation while peeing and release/Foul-smelling release from the genitourinary zone. 3785 disability cases were found in 20152016, of which there were a maximum of 1548 (40.89\%) vision impairment cases followed by common learning disorder cases with 542 (14.31\%) numbers. In 2017 the total cases coming under disability are 2787 of which neuromotor impairment cases were the highest with 667 (23.93\%) numbers and motor Delay cases were the next with 595 (21.34\%) numbers. In 2018 the total cases under this section are 3929 , in which language delay cases are topping the list with 781 (19.87\%) numbers followed by neuromotor impairment cases with 667 (16.97\%) numbers. During the years 2019 and 2020 the total number of cases under this category are 4590 and 625 respectively of which vision impairment, hearing impairment, and learning disorders have mostly occurred. While studying the data, it is observed from the trends in disabilities for the selected period that the occurrence rate of vision impairment and language delay disorders was much higher.

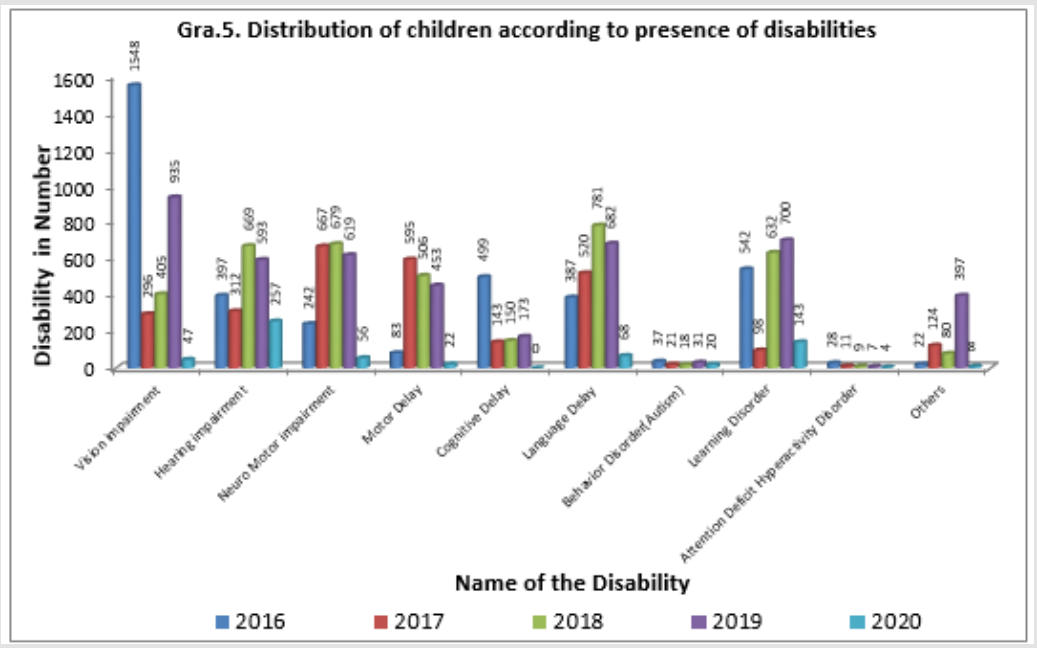

Graph 5: Distribution of children according to presence of disabilities.

On investigation of the institutional amenities like manpower and diagnostic services accessible in the DEIC, it is observed that the posts of a pediatrician, dental specialist, physiotherapist, optometrist, audiologist cum speech therapist, early interventionist cum exceptional instructor, lab technician, staff nurse-1, staff nurse-2, and social worker were filled as per the sanctioned strength and they were working throughout the study period. The post of a medical officer, psychologist, and manager stayed empty all through the examination time frame. Pediatricians and $40 \%$ of supporting staff are having knowledge of genetic testing 
and awareness towards genetic disease management. Regular record maintenance is taking place in this center; however, much information related to genetic disorders is missing. Also observed that the center does not have genetic counselors. It was found that there are no investigation facilities for genetic diseases. Related diagnostic tests were virtually non-existent in the center with the exception of basic blood, serum, and urine diagnostic tests. The needy children are being referred to $\mathrm{KGH}$ or private diagnostic laboratories for specific genetic tests and for confirmation.

\section{Discussion}

BD's are persisting throughout the world. Due to the high mortality rate of affected infants in low-income countries, it can be admitted that the impact of birth defects is higher in these countries. Even in the children who have BD's and still survive, due to no timely intervention, these disorders are causing irreversible lifetime complications with mental or physical disabilities and these children are about 3.2 million in number around the world per each year [7]. The present study found a significantly increased prevalence of BD's in children in the selected region. Our study revealed that a total of 26,423 cases were admitted through the 5 years period. This prevalence is higher than that reported by prajna Bhide and Anita Kar wherein it was stated that the affected births with surveillance of congenital anomalies are as many as 472,177 in India each year [8].

The findings of the present study reveal that the gender distribution of admitted patients is 14932 (56.51\%) male and 11491 (43.48\%) female. Such a study is also made in the past by Valla et al and it was identified that the male sex is associated with a high risk of having DD's [9]. Another previous study by Dabar et al. illustrates that there is no relationship between gender and DD's [10]. With regard to BD's, our findings provide evidence of the rise of these defects over time. Majority children had congenital deafness (218; 22.66\%) followed by cleft lip \& palate (212, 22.03\%). Our study confirms the findings of several other studies which reported that the prevalence of congenital deafness is more in India and 63 million people suffer from significant auditory loss, due to a lack of skilled manpower and human resources for the management of these defects [11]. The second most common defect was cleft lip \& palate. Our estimates however have to be considered as bestavailable data, as previous analysis on the cleft lip in south India also reported similar findings $[12,13]$.

In respect of deficiencies, during the selected study period the most common deficiency was severe acute malnutrition with 1519 (68.14\%) cases followed by severe anemia with 430 (19.29\%) cases. Our findings are also supported by one of the previous surveys conducted by measuring weight for height during a ten-year period which states that children under the age of five years are mostly suffering from severe acute malnutrition [14]. Regarding anemia, similar findings reported by Avina Sarna et al., who identified that the prevalence of anemia is higher from newborns to adolescents in India [15].

Regarding diseases, it is observed that most of the children had dental caries. The admission trend of these cases is high in 2016 and then declined in the next year and again rises from 2017 to 2019. Previous findings by Abhishek Mehta et al., are supporting these trends, wherein it was reported that a large number of Indian children have been affected by dental caries [16]. In the present study, we also observed a gradual declining trend of otitis media, skin conditions, and reactive airway disease. Similar findings were observed in the previous studies that the prevalence of otitis media [17], skin conditions [18], and reactive airway disease [19] are low during the past years. This is probably due to the reason that the people are now much aware of these diseases, and they approach the health care personnel in time.

From the side of disabilities, vision impairment has occurred in most of the children in about 3231 (20.55\%) numbers and the occurrence was alternatively rising and declining through the years. Similar findings were observed by Murthy et al., that the incidence and prevalence of loss of sight in children is varying during their study period in India [20]. This was followed by language delay with $(2438,15.51 \%)$ cases, and their occurrence has risen from 2016 to 2018 and then declined. Overall, these results are slightly higher when compared to the prevalence in developed countries as reported by Wren [21]. The present study reveals that the trend of admission of neuromotor impairment cases was being consistent with a large number up to 2019 and then diminished. In the past, population-based studies reported that the neurological disorders in rural India are higher and were found in about 6-8 million people [22]. The present study divulges that the peak incidence of deafness was during 2018; and this finding corroborates with the study findings of Nagapoornima et al. wherein it was reported that due to failure of timely screening of newborns, most of them are facing hearing impairment in India [23].

Institutional facilities are labor and infrastructural facilities and are important in offering quality assistance to children regarding genetic disease management. In the present study, on examining the manpower we observed that the medical officer, psychologist, and manager were not available throughout the study period. Due to the non-availability of manpower in such key posts, there is a devastating effect on the treatment of the kids with DD's. The rest of the working staff from DEIC, Visakhapatnam are well aware of their respective duties in the management of these disorders. Further, only basic biochemical tests are being conducted in the center and there are no specific genetic testing facilities available here. Private diagnostic laboratories in the city are being referred to for genetic tests. With regard to public health concerns, Institutional facilities form the foundation for improving public health. The entire 
public health services are dependent on the availability of basic infrastructural facilities and manpower capacities [24].

\section{Conclusion}

Through this study, the institutional facilities at DEIC, Visakhapatnam as well as the high incidence of birth defects in Visakhapatnam district were observed. The study discloses the need for strengthening management services for these disorders in this region so that the prevalence of birth defects can be minimized. National health agencies use such data for the design and evaluation of birth defects. The proposals for better management of birth defects in the selected area are; increasing the number of genetic testing units, improving the skills and expertise of the health care personnel with respect to birth defects, and developing national policies for reinforcing related services. In addition, more extensive studies are needed across the nation to determine the distribution of birth defects and their causes for overall understanding and management of the same.

\section{Statements}

\section{Acknowledgments}

The authors would like to thank all the study participants for being part of the study and all staff at DEIC Visakhapatnam for their co-operation. The authors would also like to thank Professor and Head of the Department of Community Medicine, King George Hospital, Visakhapatnam for the kind cooperation and consent to execute the study.

\section{Statement of Ethics}

This is a case report study and does not include the experiment on animal and human subjects. Written informed consent was taken from the study health organization before the data collection and personal identifiers were removed during the data analysis. The approval for this study was obtained from the Andhra University ethical committee. Approval No: IEC30 dated: 27 $7^{\text {th }}$, April-2019 and Institutional Ethics Committee of Andhra Medical College, Visakhapatnam, India on $24^{\text {th }}$, june, 2020.

\section{Conflicts of Interest}

The authors declare that there are no conflicts of interest regarding the publication of this article.

\section{Funding}

The present research work was funded by the Indian Council of Medical Research, New Delhi, India in the form of a Research Associate from the Department of Biochemistry, Andhra University, and Visakhapatnam.

\section{Authors' Contributions}

Dr.P.Koteswara Rao (corresponding author) working as a research associate from Biochemistry department, Andhra
University, Visakhapatnam, India and Prof T.Raghava Rao working as a senior professor from Biochemistry department, Andhra University, Visakhapatnam, India and both have substantial contributions to the design and interpretation of data for the work.

Koteswara Rao Pagolu: Conceptualization, Methodology, Data Collection.

Raghava Rao Tamanam: Investigation, Supervised, Writing \& Editing.

\section{Data Availability Statement}

This is an observational study done at the DEIC Visakhapatnam and the availability of the data is accessible upon request to the corresponding author.

\section{References}

1. Turnpenny PD, Ellard S Emery's (2005) Elements of Medical Genetics. Elsevier Churchill Livingstone.

2. Shevell M, Ashwal S, Donley D, Flint J, Gingold M (2003) Practice parameter: evaluation of the child with global developmental delay: report of the Quality Standards Subcommittee of the American Academy of Neurology and The Practice Committee of the Child Neurology Society. Neurology 60: 367-380.

3. Boyle CA, Boulet S, Schieve LA, Cohen RA, Blumberg SJ (2011) Trends in the prevalence of developmental disabilities in US children, 1997-2008. Pediatrics 127: 1034-1042.

4. (2013) Ministry of Health and Family Welfare Government of India. Rashtriya Bal Swasthya Karyakram (RBSK) Child Health Screening and Early Intervention Services under NRHM. Oper Guidelines.

5. Cioni G, Inguaggiato E, Sgandurra G (2016) Early intervention in neurodevelopmental disorders: Underlying neural mechanisms. Developmental medicine \& child neurology 58(4): 61-66.

6. Rosenberg SA, Zhang D, Robinson CC (2008) Prevalence of developmental delays and participation in early intervention services for young children. Pediatrics 121: 1503-1509.

7. Christianson A, Howson C, Modell B March of Dimes (2006) Global report on birth defects: the hidden toll of dying and disabled children. The March of Dimes Birth Defects Foundation. White Plains, New York p. 1-85.

8. Prajkta Bhide, Anita Kar (2018) A national estimate of the birth prevalence of congenital anomalies in India: systematic review and meta-analysis. BMC Pediatrics 18: 1-10.

9. Valla L, Wentzel Larsen T, Hofoss D, Slinning K (2015) Prevalence of suspected developmental delays in early infancy: Results from a regional population based longitudinal study. BMC Pediatrics 15: 215.

10. Dabar D, Das R, Nagesh S, Yadav V, Mangal A (2016) Acommunity based study on growth and development of under-five children in an urbanized village of south Delhi. Journal of tropical pediatrics 62: 446-556.

11. Garg S, Chadha S, Malhotra S, Agarwal AK (2009) Deafness: Burden, prevention and control in India. National medical journal of India 22: 79- 81.

12. Sridhar K (2009) A community-based survey of visible congenital anomalies in rural Tamil Nadu. Indian Journal of Plastic surgery 42: 184191.

13. Allagh KP, Shananna BR, Murthy GVS, Ness AR, Doyle P, et al. (2015) Birth prevalence of neural tube defects and orofacial clefts in India: a systematic review and meta-analysis. Plos one 10(3): 1-15. 
14. (2016) International Institute for Population Sciences (IIPS) and Macro International. National Family Health Survey (NFHS-4), 2015-16: India Fact Sheet. Mumbai: IIPS 2016.

15. Avina Sarna, Akash P, Sowmya R, Praween KA, Rajib A, et al. (2020) Characterisation of the types of anaemia prevalent among children and adolescents aged 1-19 years in India: a population-based study. The Lancet Child \& Adolescent Health 4: 515-525.

16. Abhishek Mehta (2021) Trends in dental caries in Indian children for the past 25 years. Indian journal of dental research 29: 323-328.

17. Chadha SK, Gulati K, Garg S, Agarwal AK (2015) Prevalence of ear diseases in the children of Delhi. The journal of laryngology \& otology 129: 425429.

18. Karthikeyan K, Thappa DM, Jeevankumar B (2004) Pattern of pediatric dermatoses in a referral center in South India. Indian Pediatrics 41: 373 377.

19. Vikram Jaggi, Alpa Dalal, BR Ramesh, Sharad Tikkiwal, Anil Chaudhry, et al. (2019) Coexistence of allergic rhinitis and asthma in Indian patients: The CARAS survey. Lung India 36: 411-416.

\section{ISSN: 2574-1241}

DOI: 10.26717/BJSTR.2021.38.006221

Koteswara Rao Pagolu. Biomed J Sci \& Tech Res

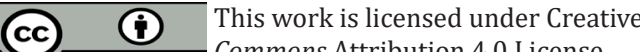
Commons Attribution 4.0 License

Submission Link: https://biomedres.us/submit-manuscript.php
20. Meenakshi Wadhwani, Praveen Vashist, Suraj Senjam Singh, Vivek Gupta, Noopur Gupta, et al. (2020) Prevalence and causes of childhood blindness in India: A systematic review. Indian journal of ophthalmology 68(2): 311-315.

21. Wren Y, Miller L, Peter JT, Emond A, Ralston S (2016) Prevalence and predictors of persistent speech sound disorder at eight years old: Findings from a population cohort study. Journal of Speech, Language, and Hearing Research 59: 647-673.

22. Gourie-Devi M (2014) Epidemiology of neurological disorders in India: Review of background, prevalence and incidence of epilepsy, stroke, Parkinson's disease and tremors. Neurology India 62: 558-598.

23. Nagapoornima P, Ramesh A, Srilakshmi, Rao S, Patricia PL, et al. (2007) Universal hearing screening. Indian journal of pediatrics 74: 545-549.

24. Maliha Batool, Trilochan Kumar (2019) Scenario of health infrastructure in India and its augmentation after independence. International journal of science and technology research 8: 2103-2107.

\begin{tabular}{|ll}
\hline BIOMEDICAL & Assets of Publishing with us \\
\hline RESEARES & Global archiving of articles \\
\hline & - Immediate, unrestricted online access \\
\hline
\end{tabular}

